\title{
Lenha e restos de madeiras como fonte de energia na Amazônia
}

\author{
John Harry Harwood ( ${ }^{*}$ )
}

\begin{abstract}
Resumo
Dados foram coletados sobre as fontes de lenha na Amazônia (desmatamento, restos de serrarias e plantios energéticos) e sobre seus processos de conversão (combustảo, carborização e ou gaseificaçāo). As vantagens e desvantagens de máquinas a vapor (locomóveis) e gasogênios são apresentadas com especial enfoque em serrarias e na geraçăo de eletricidade em municipios. É demonstrado que a lenha é um combustivel rico, versátil e que os problemas em ampliar usa utilização são mais institucionais do que técnicos.
\end{abstract}

\section{INTRODUÇÃO}

A madeira sob a forma de lenha é a fonte mais antiga de energia na história do homem. Ainda hoje o uso de lenha representa $46 \%$ de todos os produtos florestais do mundo e no Brasil as contribuições da lenha e do carvão vegetal ao quadro energético do país superaram a de hidreietricidade até 1977 (Ministério de Minas e Energia, 1978). Contudo a indústria de ienha quase não possui infra-estrutura e várias tentativas para explorar a energia de madeira fracassaram.

$\mathrm{O}$ objetivo deste trabalho foi de investigar as fontes de lenha e seus processos de conversão para pcder avaliar os potenciais $e$ as limitaçôes desta fonte de energia.

\section{MATERtaIS E MÉTODOS}

O uso e produção de lenha e/ou restos de madeira foram investigados em várias localidades: Barcelos (AM), Ric Branco (A.C), Xapuri $(A C)$, Brasiléia (AC), Aripuanã (MT), Juiná (MT) e Fontanillas (MT). Dados foram também obtidos da fazenda Link \& Cia. Ltda. (Estrada Rio Branco-Xapuri) e de Fazendas Unidas Ltda. (Estrada Manaus-Itacoatiara Km 144)
Dadios sobre a geração de eletricidade através de locomóveis foram adicionalmente obtidos dos escritórios da ELETROACRE (Rio Branco) e CELETRAMAZON (Manaus).

Vários Institutos com "know-how" especializados foram visitados, obtendo-se dados referenies à tecnologia de conversão de lenha em energia útil. Estas visitas incluiram: Mernak. S/A. Cachoeira do Sul (RS), fabricante de máquinas a vapor; CESP (São Paulo), especialista em gaseificação de madeira; IPT (São Paulo) especialista em gaseiticação de carvão vegetal para a produção de metanol; Lorenzetti S/A. (São Paulo) fabricante de gasogênios para veículos.

Para fins de comparação de preços expressos em CrS, podem ser aplicadas as taxas de câmbio seguintes: setembro 1979 USS $1=\mathrm{CrS}$ 30,00 , fevereiro 1980 US\$ $1=\operatorname{Cr} \$ 45,00$, dezembro 1980 USS $1=$ Cr\$ 60,00 .

\section{Resultados}

O calor de combustão da lenha é usado para cozimento doméstico em quase todas as cases fora das cidades; em padarias ( 40 achas/ 120 pães simples em Barcelos); no cozimento de tijolos $\left(30 \mathrm{~m}^{3} / 10.000\right.$ tijolos $)$ e para gerar vapor esterilizante numa fábrica de palmitos em lata.

Dois tipos de motores foram observados: locomóvel (máquina a vapor) que utiliza lenha picada ou restos de madeira e o gasogênio que utiliza carvão vegetal.

Locomóvers - Há somente um fabricante de máquinas a vapor no país. Uma descrição geral dos modelos é dada na tabela 1. Como a vida útil de um locomóvel é longa existem ainda velhos locomóveis importados e também modelos obsoletos da Mernak S/A. (8, 18 e 36 HP operando satisfatoriamente.

(*) - Instituto Nacional de Pesquisas da Amazônia, Manaus. 
LOCOMÓVEIS EM SERRARIAS - Todos os donos de serrarias equipadas com locomóveis mostraram-se muito saisfeitos com o desempenho e economia dás máquinas. Também muitas das pessoas que atualmente usam motores diesel gostariam de mudar para vapor mas ainda não o fizeram por faita de capital.

O consumo de óleo diesel está em torno de 5 litros por $\mathrm{m}^{3}$ de toro serrado (Tab. 2). 0 diesel chega em lugares remotos a um custo alto, devido às dificuldades de comunicação, longas distâncias além de estradas e pontes percárias. Por exempio: Aripuanã fica a 7 horas por estrada do posto de abastecirnento mais perto. O transporte de diesel por estrada aumenta o preço do litro cerca de CrS 5,00 . Contudo, durante a estação de chuva, quando a estrada está intransitável e o combustível é transportado por avião, o frete custa $\mathrm{Cr} \$ 80,00$ por litro acima do preço de compra do óleo. Por esta razão, aliada às dificuldades do escoamento da produção, serrarias em tais locais freqüentemente suspendem suas atividades neste período.

Frente aos problemas de suprimento de combustível, o uso de vapor parece muito mais atrativo, mas há vários fatores que restringem o uso de vapor nas serrarias. Primeiramente, os grupos explorando madeira são muitas vezes pequenos e geralmente lhes falta capital. Inicia-se o comércic usando-se uma serra de 18 até $32 \mathrm{HP}$, enquanto o menor locomóvel disponivel é de $40 \mathrm{HP}$. Segundo, o locomóvel cus- ta cerca de 2,5 vezes o preço de um motor diesel e suas dimensões e peso sảo enormes (Tab. 1). Terceiro, o fabricante de locomóveis está situado na extremidade oposta do país (RS), o que aumenta consideravelmente os custos de transporte da máquina e diminui a agressividade do fabricante no mercado do norte.

Além dos problemas de suprimento de óleo diesel foram notados dois fatores a favor do uso de locomóveis em serrarias: Primeiro, a vida de um locomóvel é longa (20 anos) o que compensa $\sigma$ alto custo inicial. Segundo, apesar da quantidade de restos de madeira variar consideravelmente (Tab. 2) assim como seu valor como combustivel (Tab. 3), em geral uma serraria produz restos de madeira em tais quantidades que apenas a metade destes queimada num locomóvel supre todas as necessidades energéticas da serraria.

LOCOMÓVEL PARA GERAR ELETRICIDADE - Se a indústria de madeira está a favor do uso de locomóveis, este não é o caso da indústria geradora de eletricidade. A CELETRAMAZON que gera eletricidade em todos os municípios do Amazonas, exceto Manaus, já desativou todos os seus locomóveis que geravam eletricidade a partir de lenha e os vendeu (13 unidades) em leilăo em 1979. A ELETROACRE também vendeu alguns dos seus locomóveis, mas ainda possui 4 usinas funcionando com lenha: Xapuri, Brasiléia, Tarauacá e Feijó. Destas usinas só Feijó não pảra durante a estação de chuva

TABELA 1 - Locomóveis nacionais

\begin{tabular}{|c|c|c|c|c|c|c|c|}
\hline & \multicolumn{3}{|c|}{ Semi-Fixas } & \multicolumn{4}{|c|}{ Estacionários } \\
\hline Força em regime constante (CV) & 40 & 70 & 90 & 90 & 100 & 130 & 180 \\
\hline Força máxima (CV) & 50 & 80 & 105 & 105 & 120 & 150 & 200 \\
\hline Peso $(\mathrm{Kg})$ & 6.100 & 8.100 & 12.200 & 12.800 & 13.600 & 16.400 & 22.000 \\
\hline Comprimento total $(\mathrm{m})$ & 4,40 & 4,70 & 5,00 & 7,85 & 8,00 & 8,97 & 9,48 \\
\hline Largura $(\mathrm{m})$ & 1,66 & 1,92 & 2,15 & 2,15 & 2,15 & 2,55 & 2,68 \\
\hline Altura $(\mathrm{m})$ & 3,05 & 3,27 & 3,40 & 3,50 & 3,50 & 3,85 & 4,20 \\
\hline
\end{tabular}

FONTE: Mernak Sy., Cachoeira do Sul, RS. 
TABELA 2 - Consumo de combustível e trabalho feito em várias serrarias na cidade de Juiná (MT)

\begin{tabular}{|c|c|c|c|c|}
\hline $\begin{array}{l}\text { Motor } \\
\text { (CV) }\end{array}$ & $\begin{array}{l}\text { Consumo diário de } \\
\text { óleo diesel (1) }\end{array}$ & $\begin{array}{c}\text { Volume de toros } \\
\text { serrados por dia }\left(\mathrm{m}^{3}\right)\end{array}$ & $\begin{array}{l}\text { Volume dos restos de } \\
\text { madeira por dia }\left(\mathrm{m}^{3}\right)\end{array}$ & $\begin{array}{l}\text { Consumo de óleo diesel } \\
\text { por } \mathrm{m}^{3} \text { de toros serrados } \\
\left(1 / \mathrm{m}^{3}\right)\end{array}$ \\
\hline 36 & • & 12 & 4,8 & - \\
\hline 18 & 15 & $2,5-4$ & 1,6 & $3,75-6$ \\
\hline 60 & 115 & 20 & $6-8$ & 5,75 \\
\hline 60 & 50 & 10 & 3 & 5,0 \\
\hline 83 & 50 & 10 & $3,2-4$ & 5,0 \\
\hline
\end{tabular}

(*) - Serraria a vapor.

por falta de lenha. Durante a visita do autor, a usina de Brasiléia estava parada por esta razão apesar de estar na estação de seca. A usina de Xapuri estava funcionando com lenha quando visitada. É interessante notar que esta usina está sendo abastecida pela segunda metade dos restos de madeira proveniente da serraria Link \& Cia., que queima a primeira metade no seu próprio locomóvel (por sinal comprado da ELETROACRE).

O problema de abastecimento com lenha é a razão mais freqüentemente citada para a desativação dos locomóveis da CELETRAMAZON. Outras são :

a) Dificuldades de usar dois locomóveis em sincronia;

b) $\mathrm{O}$ acréscimo rápido na demanda de energia tornou alguns locomóveis inadequados já no momento da instalação. Este fato é certamente verdadeiro nas cidades maiores do interior, como por exemplo Benjamin Constant, mas ainda hoje metade das usinas da CELETRAMAZON tem uma ponta de carga inferior a $100 \mathrm{kw}$, isto é, dentro da faixa de potência que pode ser fornecida por um locomóvel;

c) O maior número de operadores necessário para cuidar de uma usina a vapor;

d) O maiơr espaço necessário na usina;

e) A resposta mais lenta a flutuações rápidas de carga;

f) O maior tempo necessário para iniciar a operação de acendimento do fogo, além do aìto custo de capita! já mencionado.
A favor do uso de locomóveis podem ser apontadas as seguintes vantagens:

a) Geram empregos nos municípios. Por exemplo, os locomóveis de Barcelos (ponta de carga $86 \mathrm{kw}$ ) necessitavam $5-6$ homens homens tirando lenha diariamente, cada homem tirando $2-4 \mathrm{~m}^{3} /$ dia, além de 2 pessoas suplementares na sala de máquinas;

b) Operam com um custo por kwh menor do que com óleo diesei. Supondo que o preço de óleo diesel seja Cr\$ 12,00 por litro, o preço da lenha poderia subir até $\mathrm{Cr} \$ 300,00$ por $\mathrm{m}^{3}$, antes do locomóvel tornar-se não competitivo. Em setembro de 1979 o preço do $\mathrm{m}^{3}$ da lenha em Barcelos era de Cr\$ 45,00 a 50,00 e em Xapuri de Cr\$ 90,00 - Cr\$ 110,00;

TABELA 3 - Algumas madeiras boas e ruins para com. bustão

BOAS :

Mulateiro (Peltogyne paniculata)

Breu (Protium heptaphyllum)

Cumaru (Dipteryx odorata)

Abiurana (Eremoluma williamii)

Abiurana de massa (Richardella manaosensis)

Paracuúba (Lecointea amazonica)

RUINS :

Imbaúba (Cecropia sp.)

Piquiá de leite

Pente de macaco (Apeiba albiflora)

Torem (Cecropia juranyana)

Andiroba (Carapa guianensis)

FONTE: Link \& Cia., Estrado Rio Branco-Xapuri (AC). 
c) Contribuem para a autonomia local, através do uso de um combustível pioduzido na própria região.

GASOGÊNIO COM CARVÃO VEGETAL - Apesar da tecnologia do gasogênio ser bem conhecida (muitos carros andavam com gasogênio durante a Segunda Guerra Mundial) somente quatro unidades foram encontradas durante este estu. do: uma para gerar eletricidade numa fazenda, outra instalada em carro VW sedam $1500 \mathrm{~d}$ : demonstração do fabricante Lorenzetti, o gascgênio do INPA, Manaus, que gira um motor estacionário de Jipe Willis e um em fase de construção pelo proprietário de uma Kombi em Rio Branco do Acre.

As características dos gasogênios Lorenzetti são fornecidas na tabela 4 . O gasogênio com carvão vegetal pode substituir a gasolina inteiramente, embora isto diminua a potência do motor em cerca de $40 \%$. (Um motor de $100 \mathrm{HP}$ com gasolina desenvolve em torno de $60 \mathrm{HP}$ com carvão vegetal). Se o motor é de alta compressão (por exemplo um motor concebido para o uso de álcool ou um motor diesel equipado com velas) a potência usando gasogênio pode chegar a $90 \%$ da nominal. No tocante a consumo $1,3 \mathrm{~kg}$ de carvão equivale a 1 litro de gasolina (Brame \& King, 1967), ou 1 $\mathrm{kg}$ de carvão por $8 \mathrm{~km}$ rodados no $\mathrm{VW}$ sedam 1500 da Lorenzetti. As desvantagens do gasogênio são: a) Peso. Por exemplo, o gasogênio de Lorenzetti aumenta o peso de um carro em $80 \mathrm{~kg}$; b) Volume. filtragem do gás é um fator de máxima importância. Os filtros ocupam um volume considerável. Dos 4 tanques montados no exterior do carro da Lorenzetti 3 são filtros; c) Quando um veículo a gasogênio está estacionado a fornalha apaga levando algum tempo para ser acendida outra vez ou então fica ace$\mathrm{sa}$, queimando combustível desnecessariamen. te.

A estas desvantagens devem ser acrescentadas ainda, a falta de uma rede de distribuição de carvão. Contudo, para quem tem um suprimento próprio de carvăo e um veículo ou motor estacionário a gasolina trabalhando durante longos períodos, o gasogênio é sem dúvida uma opção econômica. É interessante notar, que a introdução do gasogênio na frota nacionão conava com incentivos oficiais. Até dezembro de 1979 a comercialização do gasogênio estava proibida mas as vantagens de sua utilização são tão evidentes que o governo liberou o comércio. Agora existem cinco fabricantes, dos quais Lorenzetti está produzindo 100 unidades por mês.

O uso de gasogênio em serrarias năo foi visto, mas será mais econômico em termos de capital do que a máquina a vapor. A conversão de um carro pelo sistema da Lorenzetti custou Cr\$ 60.000,00 em fevereiro de 1980. Contudo o gasogênio necessita da produção de carvão vegeta! como atividade intermediária o que torna o seu uso em seriarias menos convenien. te do que o locomóvel.

TABELA 4 - Características dos gasogênios Lorenzetti para VW Sedan 1500 e caminhão Ford ou Chevrolet

\begin{tabular}{|c|c|c|}
\hline & CARRO & CAMINHĀO \\
\hline Instalação & $\mathrm{Na}$ parte traseira & $\mathrm{Na}$ parte da frente \\
\hline Peso & $80 \mathrm{~kg}$ & $220 \mathrm{~kg}$ \\
\hline Consumo & $\begin{array}{l}1 \mathrm{~kg} \text { de carvẫo e } 0,3 \mathrm{~kg} \text { de água para } \\
10 \mathrm{~km}\end{array}$ & $\begin{array}{l}1 \mathrm{~kg} \text { de carvão e } 0,3 \mathrm{~kg} \text { de água para cerca } \\
\text { de } 3 \mathrm{~km}\end{array}$ \\
\hline Abastecimento & $\begin{array}{l}\text { A cada } 60 / 70 \mathrm{~km} \text { é abastecido com } 7 / 8 \mathrm{~kg} \\
\text { de carvão vegetal }\end{array}$ & $\begin{array}{l}\text { A cada } 50 / 60 \mathrm{~km} \text { é abastecido com } 15 / 20 \mathrm{~kg} \\
\text { de carvão vegetal }\end{array}$ \\
\hline Desempenho & $\begin{array}{l}80 \mathrm{~km} / \mathrm{h} \text { no plano } 50 / 60 \mathrm{~km} / \mathrm{h} \text { nas subidas } \\
\text { regulares }\end{array}$ & $\begin{array}{l}80 \mathrm{~km} / \mathrm{h} \text { no plano com carga; nas subidas de- } \\
\text { vem ser sempre usadas marchas reduzidas }\end{array}$ \\
\hline
\end{tabular}




\section{DISCUSSÃo}

Goodland et al. (1978) descreveram uma serraria acionada por locomóvel como sendo a única unidade industrial além da nuclear regeneradora, que produz mais combustível do que consome. Apesar disto ser verdade somente quatro serrarias foram encontradas que aproveitam dos seus restos de madeira. Os problemas com a utilização de vapor em vez de diesel já foram mencionados e é possível que o maior deles, a falta de capital, possa ser superado por incentivos fiscais no financiamento de máquinas a vapor. Contudo, há outro aspecto que dificulta o aproveitamento de restos de madeira como fonte de energia nas cidades do interior: o cuso artificialmente baixo da energia elétrica. Durante a visita do autor a Rio Branco do Acre (Agosto de 1979) a ELETROACRE faturava por mês somente $\mathrm{Cr} \$ 7$ milhões da venda de eletricidade, enquano estava gastando $\mathrm{CrS}$ 12 milhões em óleo diesel. Conseqüentemente, a energia elétrica que está sendo altamente subvencionada nas usinas termelétricas estimula as serrarias a usar este tipo de energia e não em aproveitar dos seus restos. Na realidade, há 26 serrarias ligadas à rede elétrica de Rio Branco e nenhuma sabe aproveitar dos seus restos. Da mesma forma a serraria de Barcelos antigamente era movida a diesel. Mudou para eletricidade pois o custo do kwh da CELETRAMAZON é bem mais barato do que meio-litro de óleo diesel necessário para gerá-lo.

Em média ơ preço de custo da geração do kwh da CELETRAMAZON em 1979 foi de Cr\$ 5,88 enquanto o preço de venda foi de apenas Cr\$ 1,60 (Universidade do Amazonas 1980).

GASOGENIO EM MOTORES DIESEL - Apesar do gasogênio com carvão vegetal ser uma tecnologia estabelecida, será mais versátil se puder substituir o óleo diesel e ou funcionar diretamente com lenha em vez de usar carvăo. $\mathrm{O}$ uso do gasogênio em motores diesel só permite uma substituição parcial do diesel (até $90 \%$ ). Há muito interesse atualmente no uso do gasogênio em tratores, já que são veículos que trabalham longos períodos sem parar em meio rural e freqüentemente carregam lastro para não escorregar, podendo por conseguinte, facilmente suportar o peso adicional de um gasogênio (Brandini, 1979 a) .

GASOGÊNIO COM LENHA - O gasogênio com lenha foi estudado no projeto 5000 da CESP (Leite, 1979) que visava a substituição parcial de óleo diesel em grandes máquinas estacionárias.

Apesar das perspectivas serem boas, há nesta altura um problema na limpeza do gás que está sendo limpo por "scrubbers", mas mesmo assim traços de alcatrões chegam às válvulas do motor smperrando-as. O mesmo problema de alcatrões existe na gaseificação de lenha para a produçẫo de metanol, já que os alcatrões reduzem a vida do catalisador de síntese. Claro, é possívei usar carvão vegetai como matéria-prima, mas mesmo assim há um limite prático no tamanho do gasogênio. Atualmente a zona de reação torna-se instável em gasogênios de mais de $4 \mathrm{~m}$ de diâmetro. (Hokanson \& Rowell, 1977).

Esses problemas não são insolúveis e futuramente será possível produzir gás ou metanol de madeira a preços bem atrativos. Contudo, é bom temperar o otimismo com a realidade dos problemas existentes nos processos atuais.

PLANTIOS DE MADEIRA PARA FINS ENERGÉTI$\cos$ - $\mathrm{O}$ estudo da CESP sobre uso energético de madeira (Leite, 1979) considera que o transporte da lenha é viável em distâncias de até $100 \mathrm{~km}$. Logicamente, se o suprimento de madeira dentro de uma área provém unicamente do desmatameno a certo momeno a fonte deve esgetar. Plantios energéticos são uma possivel solução. Vários estudos sugerem safras de 25 a 54 toneladas de madeira seca em estufa por hectare por ano (Love \& Overend, 1978). Contudo, alto rendimento implica no uso de fertili. zantes, inseticidas $e$ irrigação durante a estação seca, com conseqüentes problemas ecológicos e hidroquímicos. Sistemas naturais de regeneração de florestas são uma opção muito atrativa ecologicamente mas ainda faltam muitas pesquisas em manejo florestal em condi. ções amazônicas.

A tabela 5 mostra uma comparação cie lenha com o etanol e óleos vegetais para fins energéticos. A lenha é atrativa em termos de 
TABELA 5 - Dados comparativos da produção de combustivel usando algumas plantas

\begin{tabular}{l|l|c|c|c}
\hline \multicolumn{1}{c|}{ Combustivel } & Origem & $\begin{array}{c}\text { Taxa de Produção } \\
\text { (Toneladas/ha/ano) }\end{array}$ & $\begin{array}{c}\text { Calor de Combustão } \\
\text { (Kcal/Kg) }\end{array}$ & $\begin{array}{c}\text { Energia Obtida } \\
\text { (Mcal/ha/ano) }\end{array}$ \\
\hline Lenha & Eucalipto & $10-32,51$ & 3000 & $30-97,5$ \\
Alcool & Cana-de-açúcar & $2,52^{2}$ & 6400 & 18,2 \\
Álcool & Mandioca & $2,02^{2}$ & 6400 & 12,9 \\
Óleo vegetal & Dendê & $2-5^{3}$ & 9516 & $19,0-47,6$ \\
\hline
\end{tabular}

(1) - Eorges e Colombaroli (1978)

(2) - Brancini (1979b)

(3) - Sovio (1979)

calorias na safra. Aliás, deve ser lembrado que ela tem uma grande vantagem sobre qualquer outro tipo de plantio (por exemplo cana ou mandioca para álcool) - a madeira do desmatamento pode ser aproveitada usando-se a mesma tecnologia que a do aproveitamento do plantio. A madeira em pé na floresta nativa. em torno de 200 ton/ha (Uhardt, 1976), representa un "prèmio", na pior das hipóteses, equivalente a 6 anos de produção do plantio.

A CELETRAMAZON está considerando a construção de uma usina piloto com uma turbina a vapor usando lenha picada em Itacoatiara. Um plantio energético fornecerá a matéria-prima para uma unidade de $6 \mathrm{MW}$. Esta experiên. cia será uma das mais importantes na história do uso dá lenha como combustível. A eficiência de uma turbina a vapor com lenha é da ordem de $25 \%$ (Love \& Overend (1978) que é duas vezes a do locomóvel $(13 \%-$ (Harwood, 1979). Mas o sucesso desta experiência dependerá principalmente do fato que desta $v \in z$ a indústria de geração de eletricidade está preocupada com a infraestrutura necessária para o suprimento da matéria-prima, que não era o caso com os locomóveis.

\section{AGRADECIMENTOS}

O autor agradece à Rockefeller Foundation pelo apoio financeiro que permitiu a execução deste trabalho.

\section{SUMMARY}

Data were collected on sources of fuel-wood in Amazonia (deforestation, sawmill-wastes and energy plantations) and on conversion processes (combustion, carbonization and/or gasification). The advantages and disadvantages of steam-engines and gasogens are presented, with special reference to applications in sawmills and generating municipal electricity. Wood is shown to be a rich, versatile fuel and the problems in expanding its use are considered to be as much institutional as tecnical.

\section{REFERENCIAS BIBLIOGRÁFICAS}

BRANDINI, Adhemar

1979a - Energia: Alternativa para Tratores. Atualidades do Conselho Nacional de Petróleo 69. 38-39.

1979b - Balanço Energético na Produçẫo de Etanol obtido de Cana-de-Açúcar, Mandioca e Sorgo Sacarino: Revisão da Literatura -- EMBRAPA,

BRAME \& KING

1967 - Solid, liquid and gaseous fuels. Arnold publishers 6a. Edição.

BORGES, Maurício H. \& COLOMBOROL, Wagner

1978 - Carvão Vegetal: opção energética para a siderurgia dos paises tropicais. Trabajjoj presentado al Congresso ILAFA - Altos Hornos, Buenos Aires - Argentina.

GOODLAND, R.; ORWIN, H.S.; TILLMAN, G.

1978 - Ecological Development for Amazonia, Ciência e Cultura, 30 (3), 275-289.

HARWOOD, John $\mathrm{H}$.

1979 - Energia Renovável na Amazônia: Pesquisas e Perspectivas. Simpósio sobre fontes alternativas para geração de energia elétrica no Amazonas. CELETRAMAZON, Manaus.

HOKANSON, A.E. \& ROWELL, R.M.

1977 - Methanol from wood waste: a technical and economic study. USDA Forest Service General Technical Report FPL 12. 
LEITE, Antonio R.C.A.P.

1979 - Aplicaçōes da gaseificação da madeira na geração de energia. Trabalho apresentado no Simpósio sobre fontes alternativas para geração de energia elétrica. CELETRAMAZON, Manaus.

LOVE, Peter \& OVEREND, Ralph

1978 - Tree Power. An Assessment of the Energy Potential of Forest Biomassin Canada. Ministry of Supply and Services, Canada.

MINISTÉRIO DAS MINAS E ENERGIA

1978 - Balanço Energético Nacional. Brasilia, 101p.
SAVIO DOMINGOS, R.L.

1979 - Amazonas pode ser maior produtor de Dendê como energia e alimento. A Crítica, Manaus, 26 de setembro.

UNIVERSIDADE DO AMAZONAS

1980 - Sugestōes para o plano de Alternativas Energéticas do Estado do Amazonas, Relatório Preliminar. Manaus. 67p.

UHARDT, E.

1976 - A Floresta Amazônica; Fonte de Energia. SUDAM, Belém.

(Aceito para publicaçăo em 05/01/81) 